\title{
PHOTOMICROGRAPHY OF PAPER FIBERS.
}

\author{
By R. E. Lofton.
}

\begin{abstract}
.
This paper describes some of the more important factors in the photomicrography of vegetable fibers, especially of those used in the paper industry. As regards illumination it is shown that the carbon arc can be advantageously replaced by an incandescent stereoptican lamp. Different types of objectives are discussed, and it is shown that the working qualities of most objectives may be greatly improved by the use of proper light filters. Three types of light filters, with general directions for preparing them, are discussed, and directions are given for determining the quality of light transmitted by filters. The purpose and proper use of the substage condenser and diaphragm are discussed. It is shown that, where an object lying in different planes is to be photographed, an objective of comparatively long focal length will give better results than one of shorter focal length, and that this arrangement requires a longer bellows extension. Other advantages of a long bellows extension are also described. Different types of photographic plates are described and suggestions as to the best type of plate to use for photomicrographic work are given. Suggestions for staining and preparing the material to be photographed are included, as well as some suggestions as to the value of photographs for permanent records and in the study and control of materials and mill processes. A short bibliography on photomicrography and related subjects is given.
\end{abstract}

CONTENTS.

Page,

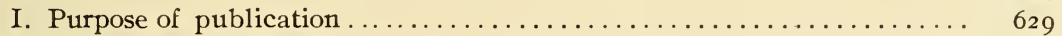

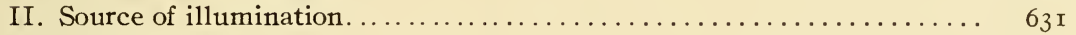

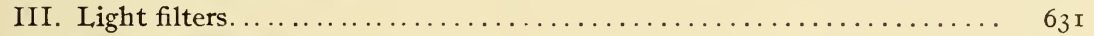

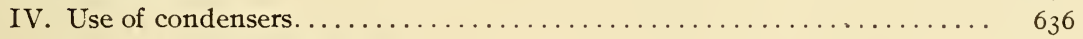

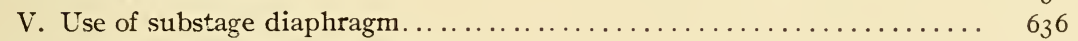

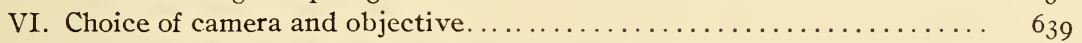

VII. Photographic plates and their development................... $6_{44}$

VIII. Value of representative field of fibers ...................... 644

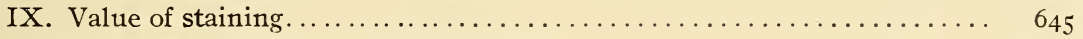

X. Photomicrographs as permanent records.................... 647

\section{PURPOSE OF PUBLICATION.}

The purpose of this paper is to put before those who desire to take up the microscopic and photomicrographic study of the vegetable fibers used in paper-making some essentials which are often overlooked, but without which the full measure of success in this field can not be had. Investigations of the value of stains, of light filters, of a long bellows camera as against one of shorter bellows, etc., have demonstrated that these factors are really 


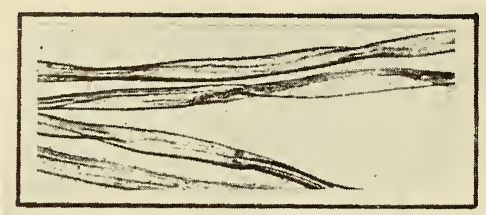

COTron (Gossypium barbadense)

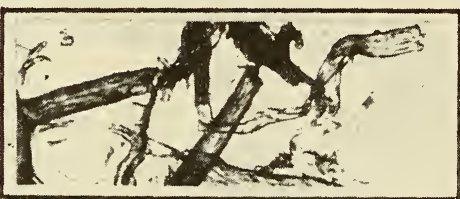

RAG PULP

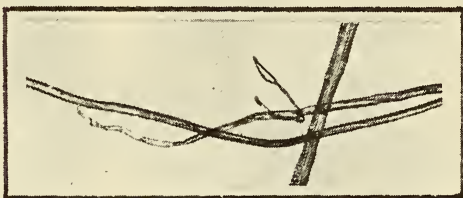

MANILA (MuSa textilis)

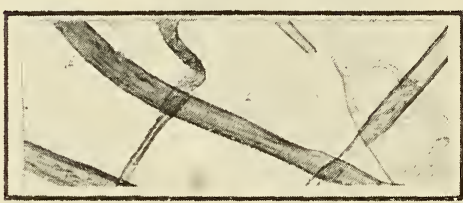

ASPEN (Populus tremuloides)

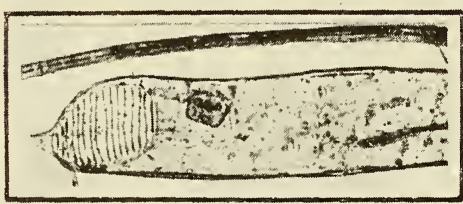

SWEET GUM (Liquidamber styracitiua)

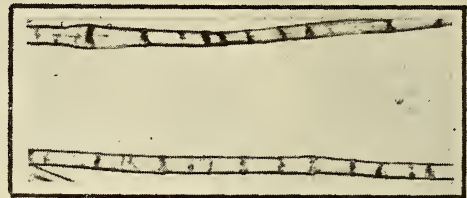

FLAX (Linum usitatissimwm)

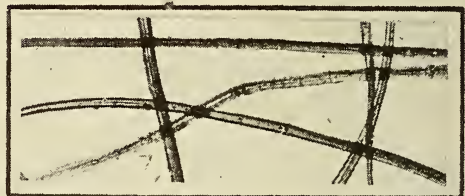

JUTE(corchorus eapsularis)

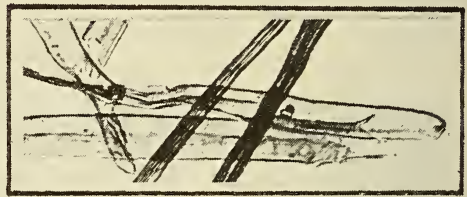

JACK PINE (Pinus diraricata)

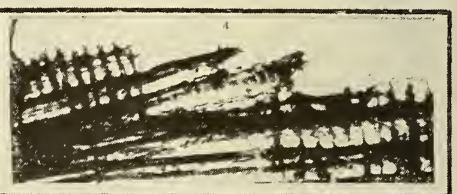

SPRUGE GROUND WOOD

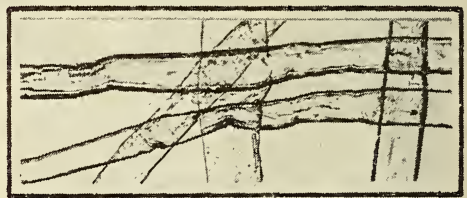

DOUGLAS SPRUGE(Psoudotsugataxifolia)

Fig. I.-Photomicrographs of some common paper fibers. $\times$ IOJ.

All vegetable fibers are fairly translucent and have central canals. Cotton is a seed hair, ribben like often twisted, blunt ends, length ro-55 $\mathrm{mm}$. Manila is a leaf-stalk fiber, round, gradually tapering ends, length $3^{-12} \mathrm{~mm}$. Flax and jute are bast fibers, cylindrical, gradually tapering ends. Flax has prominent cross markings, often $\mathrm{X}$-shaped. Jute has fine longitudinal lines. L,ength: Flax, 4-66 mm; jute, I-5 mm. Wood fibers come from the trunk and larger branches of trees. Aspen and sweet gum are broadleaf trees; fibers are cylindrical, tapering ends. Broad-leaf woods are characterized by comparatively large tubular vessels having numerous pores and sometimes bars across either end. Length of broad-leaf fibers: $0.5^{-2.5}$ mm. Jack pine and Douglas spruce are coniferous trees, fibers ribbon-like, blunt or rounded ends, much broader than cotton, and have frequent pores. Length coniferous fibers, $1.5-6.0 \mathrm{~mm}$. Ground wood is characterized by frequent bundles of fibers showing very distinct cross cells, by broken and mutilated fibers, and by extreme variation in size of particles. 
essential in the microscopy and especially the photomicroscopy of fibrous materials.

Equally essential, however, is a thorough familiarity with the laws and properties of light and lenses, with the proper use of the microscope and the functions of its various parts, and with the nature and properties of developers and the photographic plate. It is beyond the scope of this paper to discuss all these subjects, and persons feeling the need of additional information will find them discussed and treated in detail in the various books and publications which are available to all. ${ }^{1}$

What is said herein regarding fibers used in paper-making will apply equally well to all fibrous materials, textile as well as paper, animal as well as vegetable fibers.

\section{SOURCE OF ILLUMINATION.}

In the beginning of these experiments a small incandescent hand-feed arc lamp was used, but the variation in intensity of illumination and the frequent adjustment of the feeding mechanism required by this light, with the consequent periodic diversion of the worker's attention, soon led to the attempt to find a substitute. The use of an incandescent light instead of a carbon arc has the additional advantage that a source of heat which has often injured or destroyed valuable equipment and delicate objects being photographed is eliminated. After some experimenting, a 300-watt Mazda stereoptican lamp with tubular bulb was substituted for the carbon arc and found to be satisfactory. Photographs at a magnification of 1000 diameters, using a Seed 23 plate and a deep blue filter, were made at a ro-minute exposure with this lamp. Finally, a new 400-watt Mazda stereoptican lamp, recently put on the market, was substituted for the 3oo-watt lamp. This new lamp is much to be preferred to the 3oo-watt, as the six filaments furnishing the light lie in a vertical plane, and may thus be turned either edgewise to the object, giving an effect similar to that of the Nernst glower, for high magnifications, or may be turned flatwise so as to illuminate a larger field for low power photomicrography.

\section{LIGHT FILTERS.}

A study of the properties of light and of optical instruments will convince the reader, if he has not already been convinced, that all optical instruments have their limitations. The best that science

\footnotetext{
${ }^{1}$ See shert bibliography at end of this publication.
} 
and art can do in the construction of achromatic objectives with the different varieties of optical glass available at present is to make a perfect correction for two colors of the spectrum, called the "preferred" or "chosen" colors. These chosen colors are brought to a point focus nearer the objective than are the other colors, which are focused at various points along the axis of the objective. (See Fig. 2.) The colors chosen for visual work are yellow and green, usually

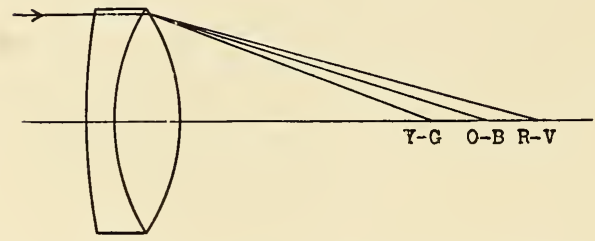

FIG. 2.-Shows objective corrected for visual use.

Yellow-green is the "chosen color" (See text for explanation).

light, but is most sensitive

to the blue-viclet region of the spectrum, objectives intended exclusively for photographic use are corrected for blue light. (See Fig. 3.) As photographic objectives of $16 \mathrm{~mm}$ equivalent focus are comparatively rare, however, almost all photomicrographic work is done with achromatic outfits constructed for visual work, unless, perchance, an apochromatic outfit is at hand.

It is evident then, since the visual focus and the photographic or chemical focus are not the same (see Fig. 4), that best results can not be expected if white light is used in conjunction with an achromatic outfit, since white light is composed of all the colors of the spectrum. Those who attempt to make photomicrographs by using an achromatic outfit and white light are faced at

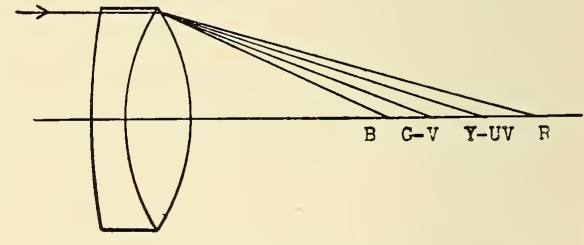

FIG. 3.-Showes objective corrected for photographic use.

Blue is the "chosen color" (See text for explanation). once with the problem as to how to make the visual and the chemical foci the same. If a good dry plate, sensitive to yellow-green only, were on the market, it would afford the most desirable solution of the problem; for a microscope objective is supposed to give the best results, other things being equal, when transmitting only those colors of the spectrum for which it is corrected. Since such a photographic plate is not to be had at the present time, 
however, the only alternative left is the use of ray or light filters, whose function it is to absorb all those rays of the spectrum not desirable for illuminating the object to be photographed.

Light filters may be purchased, or may be made in the photographic workroom which will transmit any portion of the spectrum, usually within rather broad limits, however. A filter should be chosen which will transmit only a very narrow band of the color of the spectrum to be used; that is, the light transmitted should be as nearly monochromatic as possible. Unfortunately, however, filters transmitting a very narrow band do not usually transmit a large percentage of the incident light.

Three different types of filters are in common use: (I) Liquid filters, made by dissolving various dyes, depending on the color of the light wanted, in their proper solvents; (2) filters made from colored glass; and (3) filters made by staining transparent films in various dye solutions.

Liquid filters have the disadvantages that they are usually not constant for any length of time in the quality and quantity of light they transmit, that the liquid of

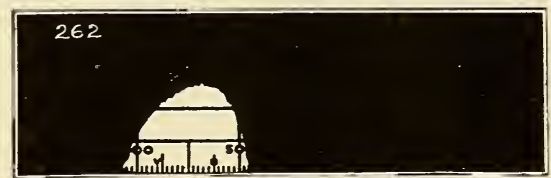

Spectrogram of Ordinary Plate.

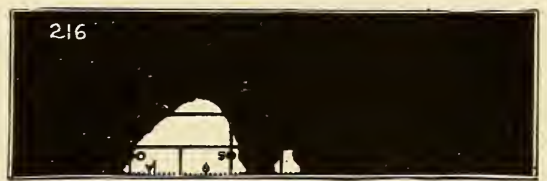

Spectrogram of Orthocromatic Plate.

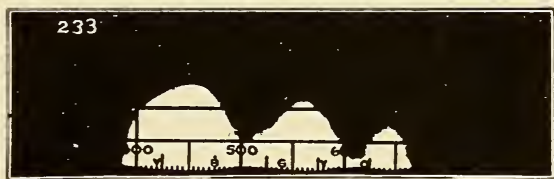

Spectrogram of Pancromatic Plate.

FIG. 4

The letters at the bottom of each spectrogram refer to the color of the light falling on the plate; $\mathrm{UV}$, ultraviolet; V, violet; $\mathrm{B}$, blue; $\mathrm{G}$, green; $\mathrm{Y}$, yellow; $\mathrm{O}$, orange; and $\mathrm{R}$, red. The numbers give the wave length of the light in millionths of a millimeter. which they are composed frequently gets spilled or leaks out over the apparatus and thus sometimes causes great injury, and that they require considerable time and care to keep in proper working condition.

Quite a number of filters made from colored films are on the market and some of them are good. There are also available glasses of various colors which make excellent filters when ground and polished properly. Neither the use of colored films, mounted on or between glass, nor that of glass filters has the disadvantages attending the use of liquid filters.

A suitable filter, often superior to most available, can be made by treating an ordinary photographic plate in a plain fixing bath 
in the dark room until all the silver salts are removed, washing, and then immersing in an aqueous or aqueous-alcoholic solution of a suitable dye for a few hours.

Although photographic plates may be had sensitive to all colors, there are various advantages in using only the shorter wave lengths of light, particularly blue light. All plates are more sensitive to blue and blue-violet light than to other colors, and so when exposed to light of this color require a shorter time of exposure. (See Fig. 4.) The use of filters transmitting only the shorter wave lengths also has the advantage of increasing the resolving power of the objective. The theoretical resolving power, $R$, of a lens-that is, the minimum distance apart of two or more dots or lines at which the lens can form a distinct image of each dot or line-is given by the formula

$$
R=\frac{\lambda}{2 \mathrm{~N} \cdot \mathrm{A} .}
$$

where $\lambda$ is the wave length of the light used and N. A. is the numerical aperture of the lens.

By the use of light filters greater contrast is had between the material to be photographed and the background, so that it is possible in this way, especially with the use of stains as suggested below, to have the printed image stand out in bold relief with no background whatever showing. If a blue filter is being used, the greatest contrast between the background and the printed image is obtained by staining the material to be photographed with red or yellow dyes. Black dyes are suitable of course with any light, provided the fibers do not take them up in such quantity as to prevent all detail of structure from showing. Dense staining must be avoided in all cases, sometimes a mere tinting being sufficient.

If one is to get the best results with light filters, there must be some practical method for determining the quality of light being transmitted by the filter used, since this can not be done by the unaided eye. The most convenient means of determining the transmission of light filters is a replica transmission grating of about $\mathrm{I}$ by 2 inches in size, having 5000 or 6000 lines per inch. To examine the quality of light transmitted by a given filter by this means, all light must be excluded from the grating except that passing through the filter. The grating must be held between the light filter and the eye, and the eye and grating directed somewhat to one side and not directly toward the light filter. The 
various colors of the light transmitted can then be seen and the quality of the filter determined.

Another solution of the problem of making the chemical and visual foci identical is the employment of an apochromatic objective and compensating ocular. If one wishes to use the objective without an ocular, however, a monochromatic filter should be used, as the apochromat is intentionally so constructed that, when white light is used, it will not give an image free from color except in combination with a compensatingocular. Notwithstanding the finer corrections of the apochromats, it is doubtful if their performance in photomicrography is much superior to that of the best achromats when used under the most favorable conditions. Besides being less expensive, the achromats have the advantage of giving a flatter image, that is, one having less curvature.

Figures 5 and 6, which are photomicrographs at a magnification of 250 diameters of a scale ruled on a glass slide, show something of the relative merits of an achromatic objective

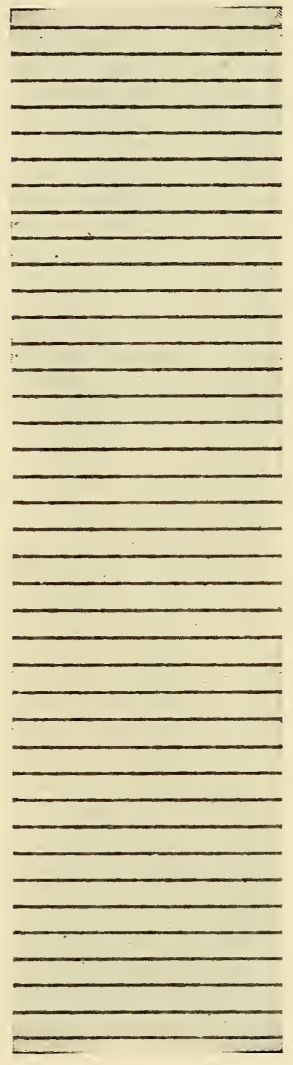

FIG. 5 .

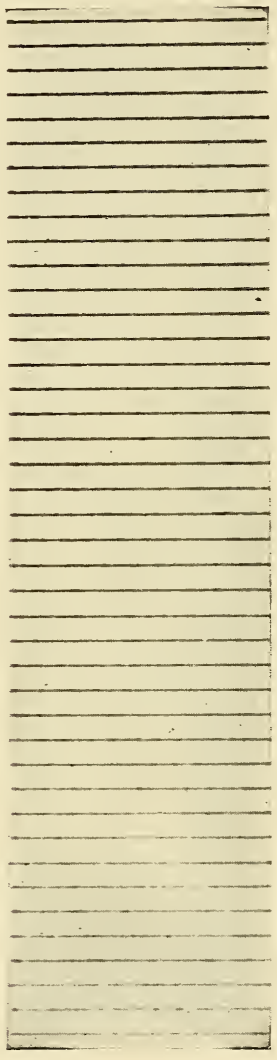

FIG. 6.

Figs. 5 and 6 . The left half of photomicrographs at a magnification of 250-times of a scale ruled on glass, show the relative flatness of image given by a $16 \mathrm{~mm}$ achromatic objective (Fig. 5) and by a $16 \mathrm{~mm}$ apochromatic objective (Fig. 6). and an apochromatic objective in giving flatness of image. Figure 5 , the scale as photographed with the achromatic objective, shows that this objective gives a slighter flatter image than the apochromatic objective, with which the same scale was photographed, as shown in Figure 6 . Both objectives have an equivalent focus of I $6 \mathrm{~mm}$. 


\section{USE OF CONDENSERS.}

For shorter focal lengths than $8 \mathrm{~mm}$ a regular substage condenser is not desirable, as better results are to be had by a condenser arrangement which will send a parallel or nearly parallel beam of light into the objective. This may be had by removing the regular substage condenser and placing at the proper point in

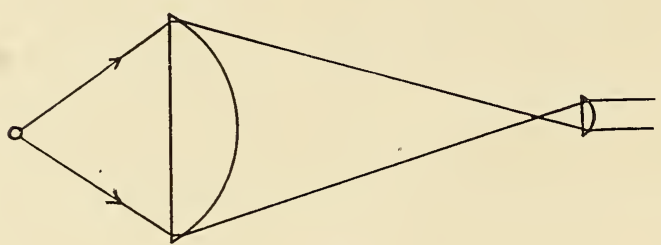

FIG. 7.-Condenser arrangement with two converging lenses. the beam of light from the large condenser either a converging or a diverging lens of short focal length and relatively small diameter. The converging lens must be placed slightly outside the point, depending on its focal

length, at which the rays are focused by the large condenser (see Fig. 7); the diverging lens, on the contrary, must be placed slightly within this point. (See Fig. 8.) This adjustment is easily carried out in a darkened room whose atmosphere contains floating particles of dust or smoke, as the path of the light rays can then be distinctly seen.

\section{USE OF SUBSTAGE DIAPHRAGM.}

It is a fact well known to all photographers that to close down the diaphragm of the camera in making a photograph increases the depth of focus or penetrating power of the lens. The only disadvantage the ordinary photographer encounters in decreasing the diameter of the diaphragm is an increase in the time of exposure. In closing the substage diaphragm, however, the photomicrographer

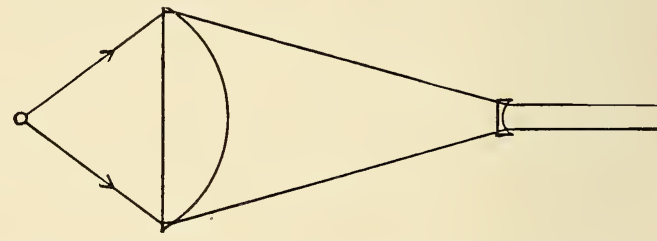

FIG. 8.-Condenser arrangement with converging and diverging lenses. encounters an additional and far greater evil, namely, the appearance of diffraction or false images which mar the definition and perfection of the real image produced by the objective. Diffraction effects are most readily produced in using objectives of short focal length, but may be produced with comparatively long 
focal lengths if the diaphragm opening is made quite small. The purpose of the substage diaphragm is to exclude all those rays of light, from whatever source, which do not assist in forming the most perfect image of which the lens system is capable. Experience will soon teach one that the best results are not to be had when the diaphragm is wide open, and that the less the numerical

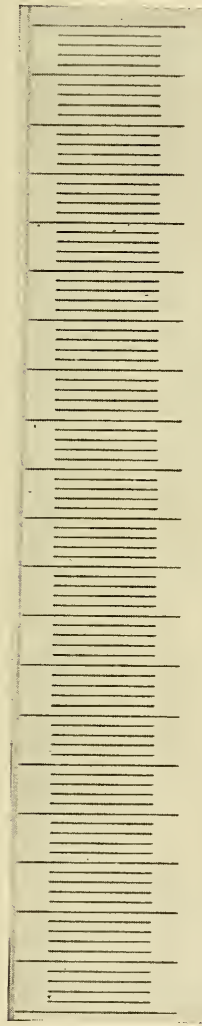

FIG. 9 .

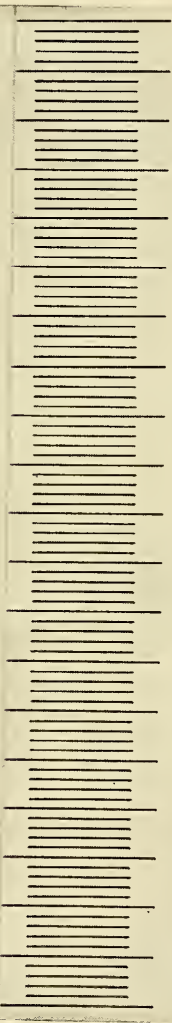

Fig. IO.

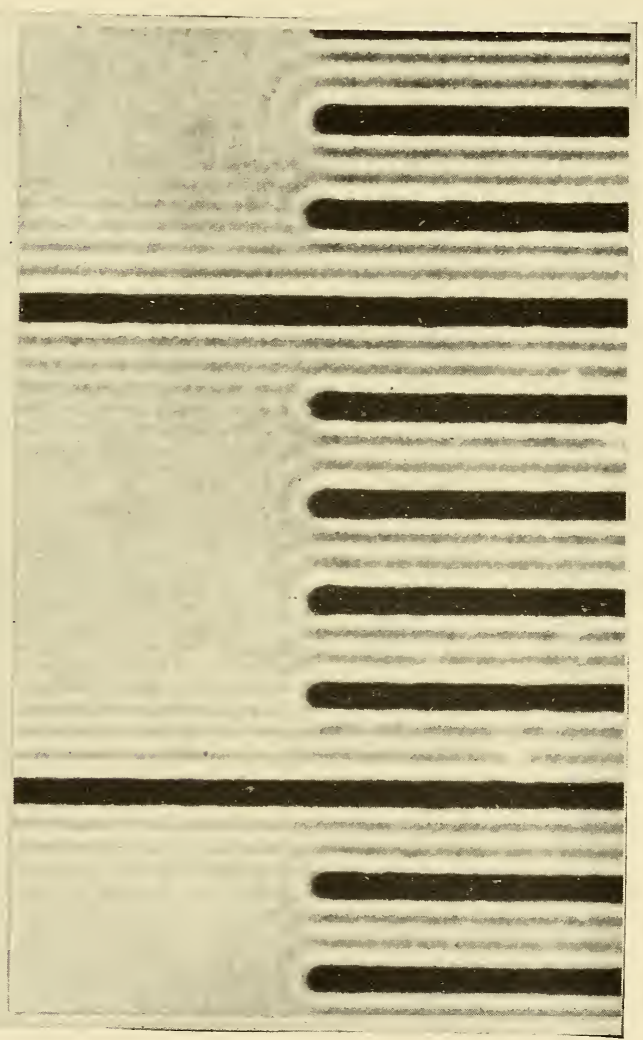

FIG II.

Figs. 9, I0, and Ir. Photcmicregraphs at a magnification of roo times of a scale ruled on glass, show diffraction effects due to the use of substage diaphragm of too small aperture. The diaphragm openings were $I_{4} \mathrm{~mm}, 4 \mathrm{~mm}$, and I $\mathrm{mm}$, respectively. Fig. I I was subsequently enlarged ro times to show more distinctly the effects of diffraction. All photographs were made with an achromatic objective of $16 \mathrm{~mm}$
focus and numerical aperture of 0.25 .

aperture of the objective the smaller the diaphragm opening must be for the best definition. It has been found that best results are obtained with most objectives if the diaphragm is closed down until only about three-fourths or three-fifths of the back lens of the objective is lighted. The portion of the back lens which is lighted can be readily determined, if the mirror is properly adjusted, by removing the ocular and looking down into the tube 
of the microscope. If the diaphragm opening is too large some of the rays of light enter at too great an angle with the axis of the optical system; when the diaphragm is much too large a large proportion of the rays enter so obliquely that there is produced what is called "flooding" of the objective with light, with the result that definition is almost or wholly destroyed. This latter condition exists, however, only with substage condensers of relatively large numerical aperture.

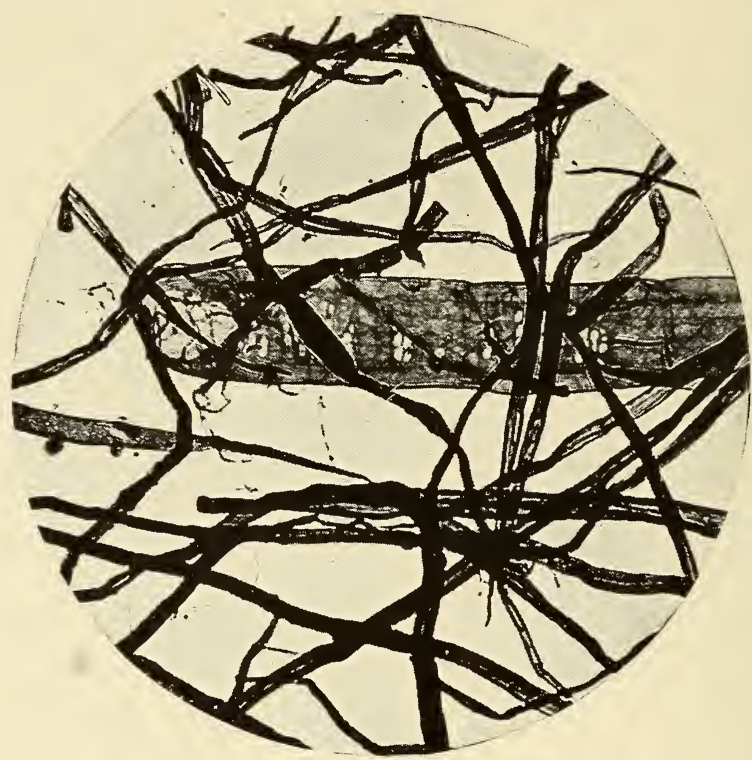

FIG. Ira.-Chemical pulp from aspen $\times$ Ioo.

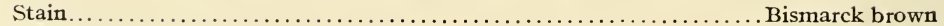

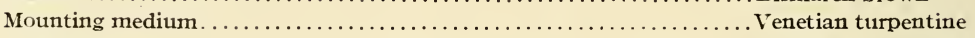

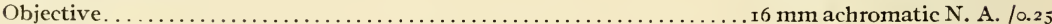

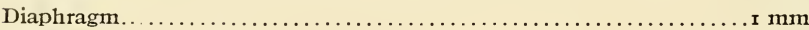

Exposure ............................................ minutes

Notice the diffraction bands-black and white lines parallel with the outlines of the fibers. "Flare pots," caused by dust particles being brought partially into focus by the aid of the small diaphragm, are evident. Compare with Fig. II and Fig. I7.

Figures 9, IO, I I, and I I illustrate these facts. In Figure 9 the substage diaphragm was full open, in Io it was closed to $4 \mathrm{~mm}$ diameter, and in I I and $\mathrm{IIa}^{2}$ it was closed as far as possible,

2 The filter used was made in the laboratory from a photographic plate and a blue dye, by the method outlined in this paper. This filter transmits a rather narrow band in the blue and violet, and a small and relatively weak band in the deep red. Instead of the regular substage condenser, an achromatic 1 ens of $50 \mathrm{~mm}$ focall ength was substituted and used throughout these experiments. In all photographs Seed No. 23 plates were used. Metol-hydroquinone developer of about double the usual strength was used for developing the plates. The same kind of developer of the usual strength was used in making the prints. All prints were made on regular glossy velox, and were rolled down onf errotype plates to dry. The Venetian turpentine used as the mounting medium was an artificial product. An attempt was made to secure some true Venetian turpentine, but without success. The artificial product, however, gave excellent results, although sufficient time has not elapsed since it was first used here to indicate anything as toits value as a permanent mounting medium. The turpentine as used had a refractive index of 1.520 at $20^{\circ} \mathrm{C}$. 
to $\mathrm{I} \mathrm{mm}$. The sharpness of definition of Figure 9 is much better than that of Io; the lines in the latter are appreciably broader because of diffraction. In Figures I I and I I diffraction effects are more apparent. Figure I I is a Io-times enlargement of the original photomicrograph made at a magnification of Ioo diameters.

\section{CHOICE OF CAMERA AND OBJECTIVE.}

Successful photomicrographs can not be made with a camera provided with a very short bellows, especially if a comparatively large photograph, an 8-inch by ro-inch, for example, is wanted at considerable magnification. If a short bellows is used, an objective of shorter focal length must be used than if the bellows were longer, and an objective of short focal length is never desirable if one of longer focal length will give the detail required in the photograph. The objective of long focal length has the following advantages over one of less focal length: (I) Greater depth of focus (2) gives a flatter image, and (3) shows a larger field. By depth of focus, sometimes called penetrating power, is meant the capacity of a lens to bring to a sharp focus at the same time an object, or objects, lying in slightly separated planes perpendicular to the axis of the lens. The depth of focus of a lens is directly proportional to the square of its equivalent focus, or focal length, and inversely proportional to its numerical aperture. A study of Figures I 2, I3, and I4
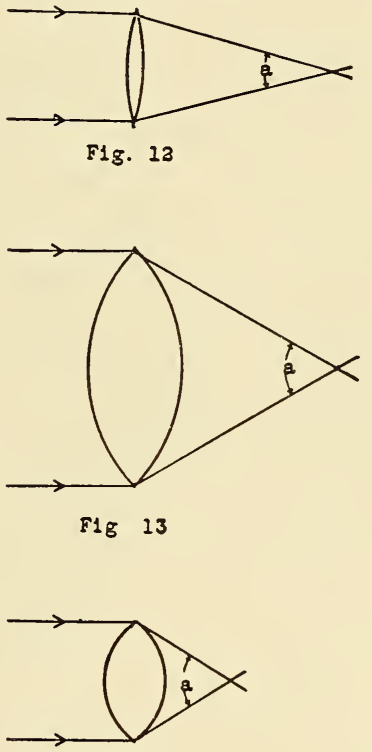

F1g 14

Figs. 12,13 and 14 . Variation in depth of focus with lenses of differen $t$ equivalent focus and different numerical aperture. $a=$ the angle which the marginal rays make in crossing at the principal focus. will show that the greater the angle $a$ which the peripheral rays make it crossing at the focusing point the less will be the depth of focus. Figures I 2 and I 3 represent lenses of the same focal length, but the diameter of $\mathrm{I}_{3}$ is much greater than that of $\mathrm{I} 2$, and it is very evident that the depth of focus of $I_{3}$ is much less than that of $I_{2}$. Figures I 2 and I4 represent lenses of the same diameter, but i4 has a much shorter focal distance than $\mathrm{I} 2$, so that the peripheral rays through $\mathrm{I} 4$ make a greater angle than through 12 ; hence the depth of focus of I4 is less than that of 12 . By the use of the diaphragm in 
photography the peripheral or marginal rays may be "stopped" out, thus decreasing the effective diameter of the lens, so that objects both relatively near to and relatively distant from the lens are in sharp focus.

Figures I 5, I6, I 7, and I 8 illustrate the increasing depth of focus of objectives of increasing focal lengths.

It is shown in treatises on light that all points of real images formed by convergent lenses do not lie in the same plane, even though the optician may have exhausted his skill in making the

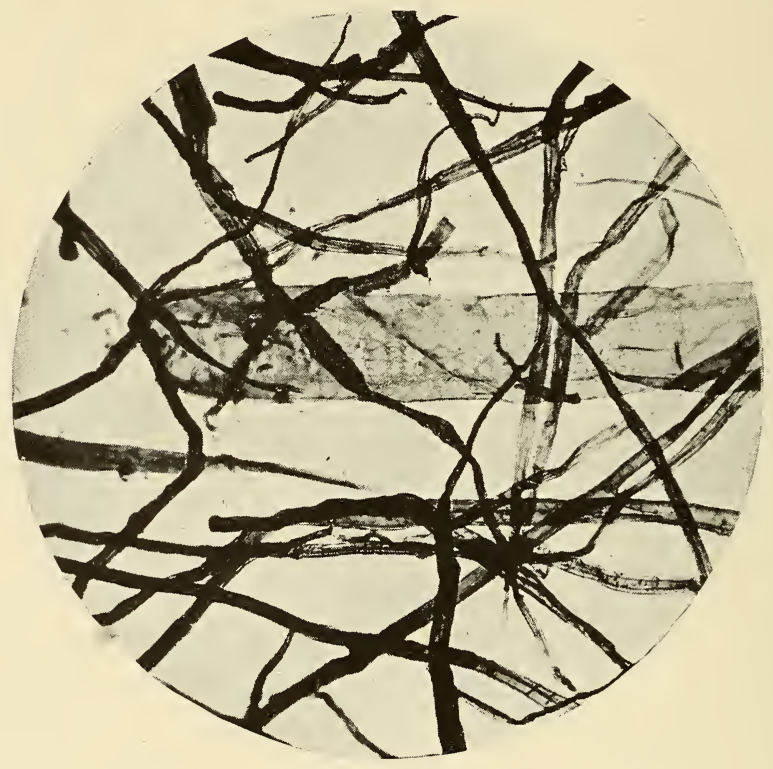

FIG. I5.-Chemical pulp from aspen $\times 100$.

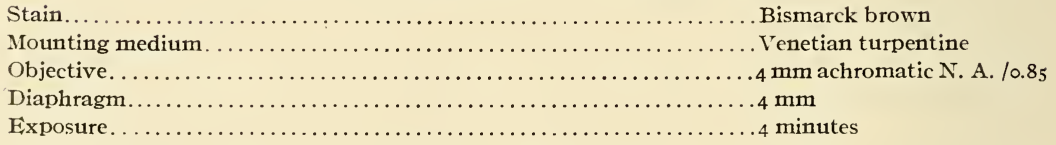

necessary corrections. Although this curvature of image is usually not evident in lenses of comparatively long focal length, it is quite evident in lenses of such short focal lengths as high power, or even moderately high power, microscope objectives. When rays parallel to the axis are incident at all points on the surface of the lens, those rays passing through the margin are brought to a focus at points nearer the lens than are those passing through nearer its center. Also, of the oblique rays passing through the center of the lens those making the greatest angle with the axis are brought to the focus nearest the lens. For these reasons the image $I$ of 


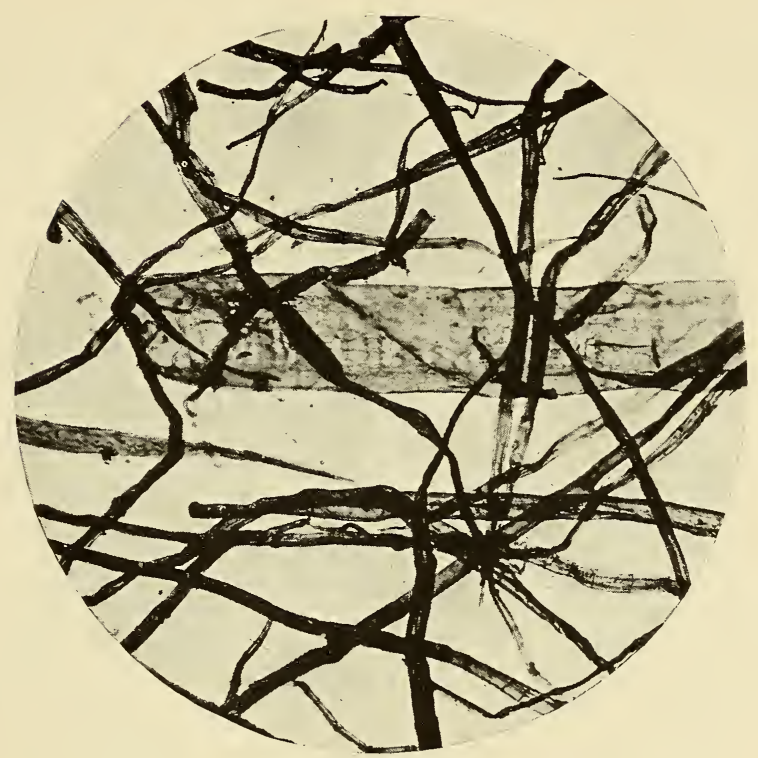

FIG. I6.-Chemical pulp from aspen $\times 100$.

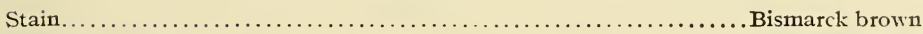

Mounting medium. . . . . . . . . .

Objective .......................................... $8 \mathrm{~mm}$ achromatic N. A. / 0.50

Diaphragm

. $.4 \mathrm{~mm}$

Exposure........................................... minutes

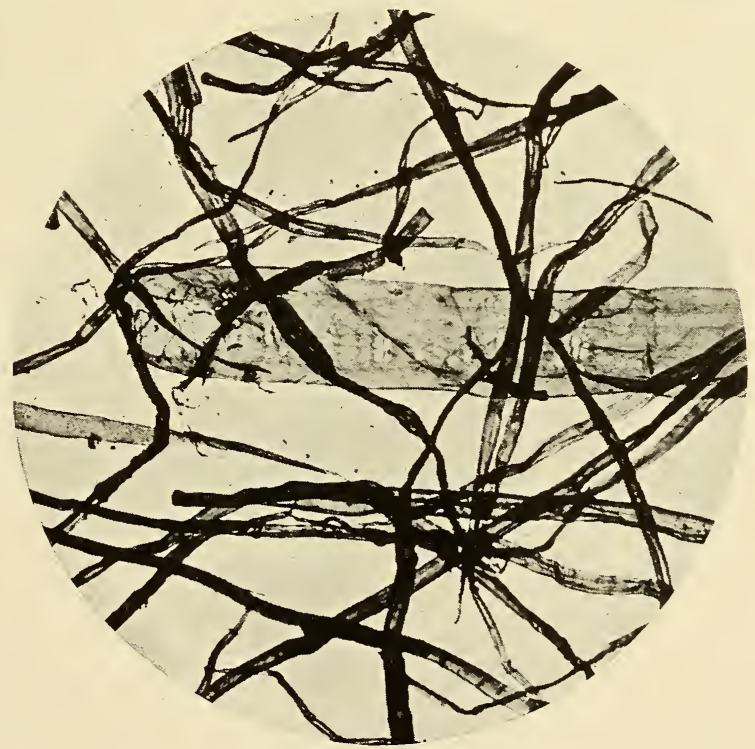

FIG. I 7.-Chemical pulp from aspen $\times$ IOo.

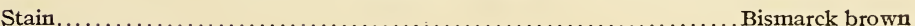

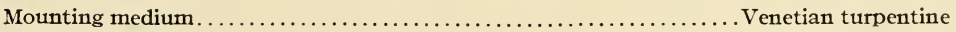

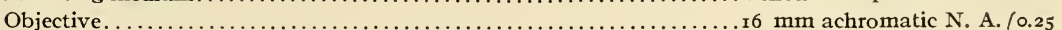

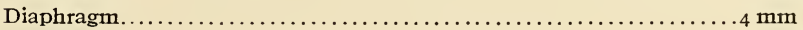

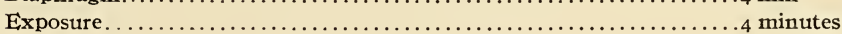


the object $O$ will take the form as shown in Figure I9. Persons using the microscope have observed this condition, in that to get objects lying near the margin of the field of view in focus after the center of the field has been sharply focused upon one has to rack the objective slightly toward the object. In objectives of longer

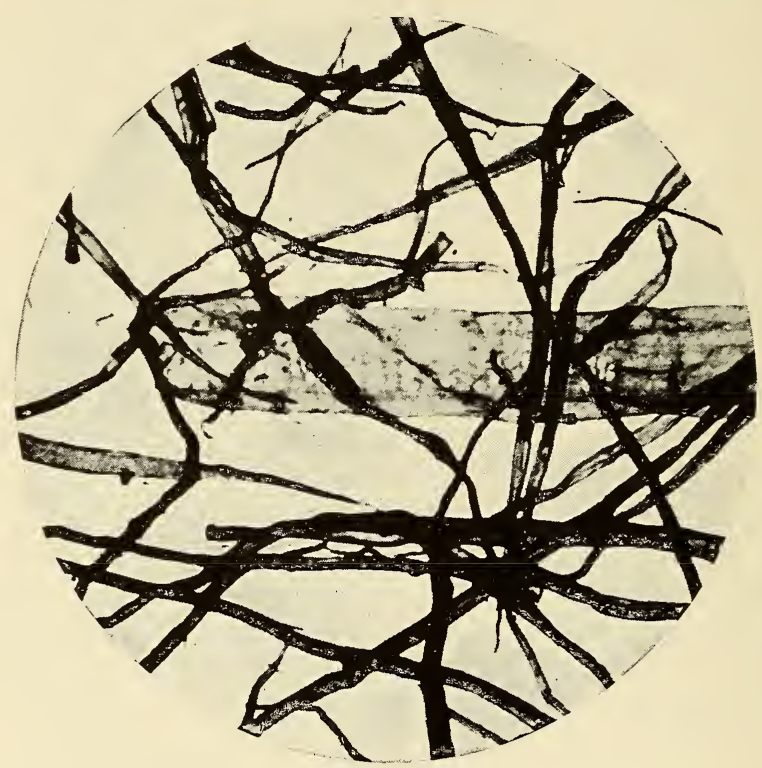

Fig. 18.-Chemical pulp from aspen $\times I 00$.
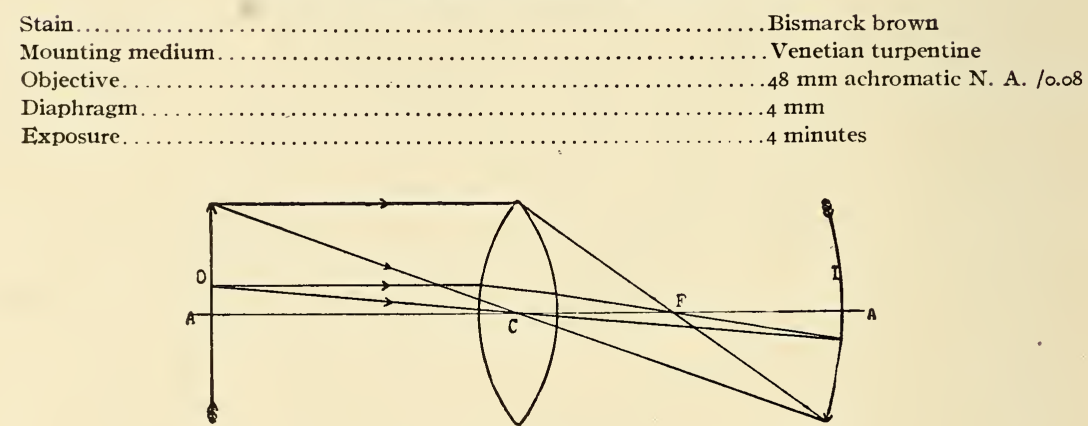

Fig. I9.-Curvature of image of a convex lens.

$O=$ object; $I=$ image; $C=$ optical center of lens; $A A=$ axis of lens; $F=$ principal focus of lens. (See text for explanation)

focal length this curvature of image does not exist to such an extent, so that it is particularly advisable to use objectives of longer equivalent focus in photomicrography if a comparatively large photograph is to be made. But an objective of longer equivalent focus will require a longer bellows unless an eyepiece of higher 
power be used, which is usually not desirable, since high-power eyepieces often unduly aggravate faults already existent, or even introduce new ones. Although compensating eyepieces must be used with apochromatic objectives unless monochromatic light is used, the use of eyepieces is not necessary with achromatic objectives, and not even desirable in most cases, if means are at hand

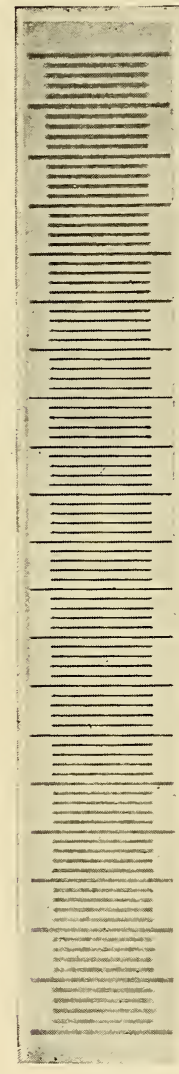

FIG. 20 .

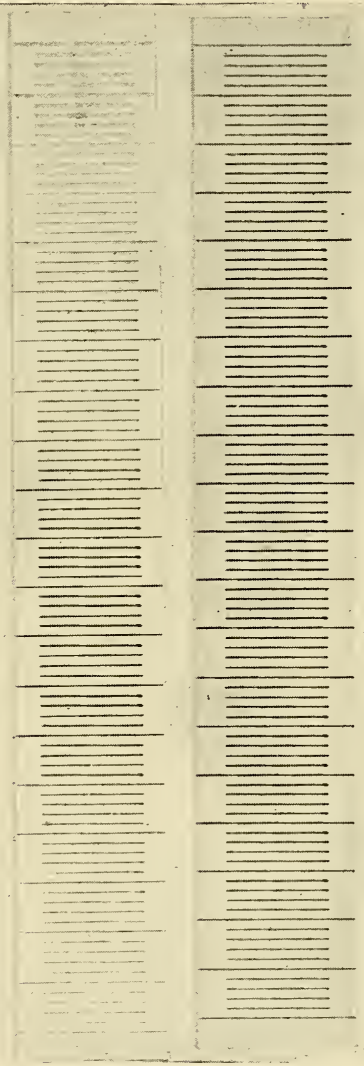

FIG. 2 I.

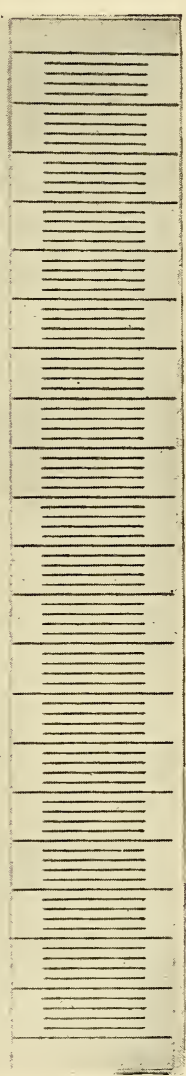

Fig. 23.

Figs. 20, 21, 22, and 23, photomicrographs at a magnification of roo times of a scale ruled on glass, show the greater flatness of image given by objectives of greater focal length. Fig. 20 was made with a $4 \mathrm{~mm}$ achromatic objective, Fig. 21 with an $8 \mathrm{~mm}$ achromatic objective, Fig. 22 with a $16 \mathrm{~mm}$ achromatic objective and Fig. 23 with a $48 \mathrm{~mm}$ achromatic objective.

for getting the desired magnification without their use. If an eyepiece must be used, it should be of very low power, not more than about two times $(2 \times)$. All the photographs shown were made with achromatic objectives, with but one exception, without the use of eyepieces.

Objectives of long focal length not only give greater depth of focus and less curvature of image, but they also give a larger field 
of view and cover a larger plate than those of shorter focal length, so that by their use a larger photograph can be made. It is also desirable that the total area covered by the image at the ground glass screen be much larger than the plate used to record the image, since then only the central portions of the image will be photographed and the best focus, as flat an image as possible under the circumstances and the best definition will be secured. Figures $20,2 \mathrm{I}, 22$, and 23 show that the curvature of the image is less with objectives of greater focal length. The glass scale was not long enough, however, to show the comparative values of the I $6 \mathrm{~mm}$ and $48 \mathrm{~mm}$ objectives in this respect.

\section{PHOTOGRAPHIC PLATES AND THEIR DEVELOPMENT.}

The selection of the dry plate to be used in making a photomicrograph is of almost as much importance as any other factor. Various plates were tried during this investigation, and it was found that good results were to be had only by using comparatively slow plates. Even with these plates a contrast developer was used and was found not to give too great contrast if the staining of the fibers was properly done. The slow plate usually has greater resolving power, due to the finer grain of the silver salts in the gelatine emulsion. These advantages will much more than compensate for the additional time of exposure required over that of the faster plate. Process plates, however, are not to be recommended for general work, as they give too much contrast. Whether one should use an ordinary, an orthochromatic, or a panchromatic plate will depend, of course, on the colors of the material to be photographed, the purpose in view in making the photograph, and perhaps on other factors.

\section{VALUE OF A REPRESENTATIVE FIELD OF FIBERS.}

It is of first importance that the microscopist should know the distinguishing properties and characteristics of the fibers which he is about to photograph and that he should take all precaution to get a representative field under the microscope. It would be manifestly wrong, for example, to make a photomicrograph of a field of aspen soda pulp which does not show any of the characteristic pitted vessels chiefly by means of which all hardwoods are distinguished from the softwoods or conifers. It also gives a wrong impression to see a photomicrograph of wood pulp showing an incorrect proportion of fibers to vessels, tracheids, or parenchyma cells. The material to be photographed, whether it be 
pulp or other material, should first be studied sufficiently under the microscope to determine its properties and characteristics, and the correct proportion of the various cells or other components, by counting or by some other reliable method. A field for photographing should then be chosen which will show the correct proportion of the various individuals or other characteristics which it is the purpose of the photographer to show.

\section{VALUE OF STAINING.}

The utility and value of the use of various stains and dyes in the differentiation and study of plant tissues and elements has long been recognized by botanists. A great number of dyes and stains of recognized worth for botanical work are on the market, and this number is being gradually added to.

A number of these stains are more or less selective in their action on plant tissue, and many of them are emphatically so. Their great value lies in the fact that because of this selective property they dye certain tissues or certain parts of fibers more deeply than others, and thus bring out or accentuate characteristic markings, reactions, or other properties of the fibers. By their use the differentiation and identification of various fibrous materials, otherwise difficult or impossible, is made quite easy and certain.

Their value in the photomicrography of paper-making fibers is greater, if possible, than in the visual study of plant fibers. One of the most serious limitations to the photographing of fibrous materials is that their finer markings and characteristics can not be shown as readily and as distinctly by photographic means as by visual means. Hence any means of showing more distinctly the characteristic markings of fibers is a manifest advantage in making a photograph of these fibers; this means is supplied by the proper use of stains.

Another great value of the use of a proper stain is the contrast afforded between the outlines of the fibers and the background. By this means the fibers may be made to stand out in bold relief, with no suggestion whatever of a background in the finished print if the work is well done.

Figures 24 and 25 show the advantages of staining in bringing out the physical features of fibers, and especially in offering sufficient resistance to the passage of the light rays through the fibers to allow the plate to be exposed long enough to prevent the background showing in the finished print. 


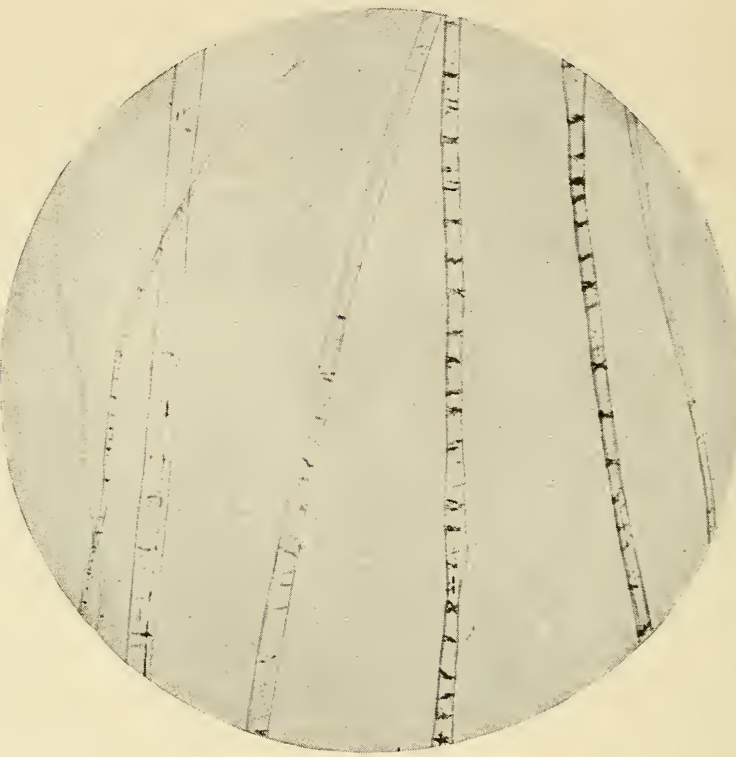

FIG. 24.-Flax fibers $\times$ IOO.

Stain Mounting medium

None

Objective.

Diaphragn

I $6 \mathrm{~mm}$ achromatic N. A. 0.25

Exposure 2 minutes
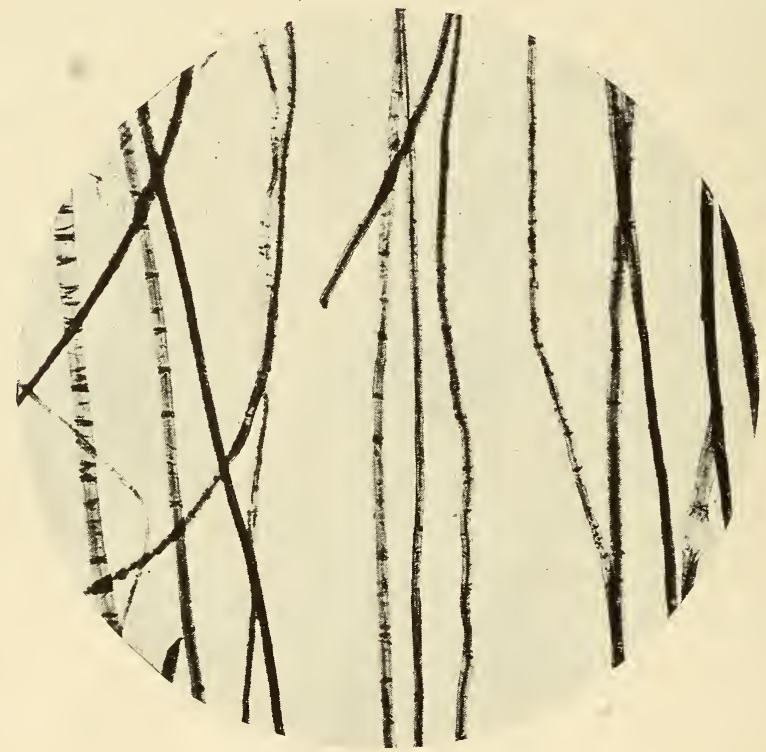

Fig. 25.-Flax fibers $\times I 00$.

Mounting medium Vcnetian turpcntine

Objective.

I $6 \mathrm{~mm}$ achromatic N. A. 0.25

Diaphragn $4 \mathrm{~mm}$

Exposure 3 minutes 


\section{PHOTOGRAPHS AS PERMANENT RECORDS.}

The use to which photomicrography may be put in the control of various industrial processes and in recording the presence of adulterations are innumerable. "Wherever the microscope finds application and permanent records of observations are required, photomicrography is the readiest, most convenient, and accurate means available. Prints can be stored with the written notes of analyses and examinations, and have not only the value of records of known facts but of points unknown or unrecognized at the time,

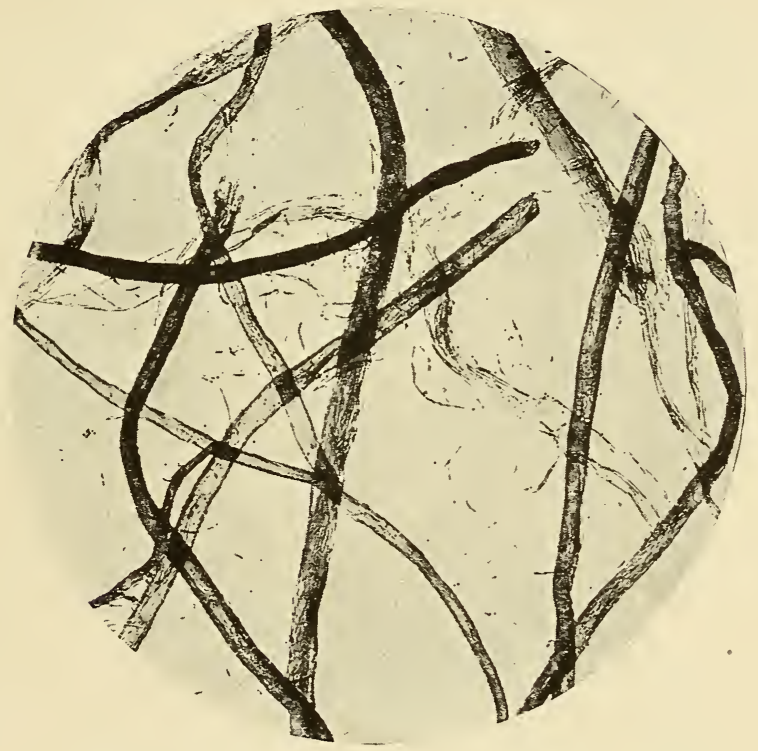

Fig. 26.-Fibers from all rag heavy ledger $\times$ IOO.

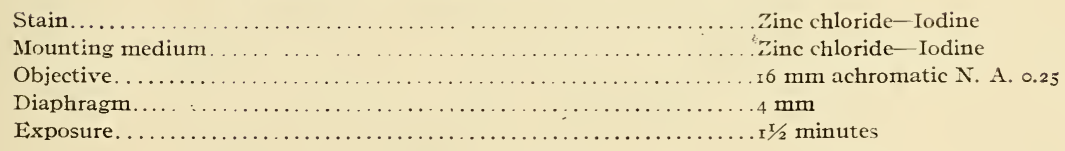

which would inevitably be missed in any written notes, but may become of the highest importance in future researches and afford accumulated evidence which it would be impossible to obtain otherwise." 3

In the paper industry photomicrography may be advantageously employed in the study and control of the cooking and beating processes, in the examination of pulps and pulp mixtures, and of sizing and loading materials, in recording adulterations frequently found in dyes, in studying bacteria and molds, dirt in pulp and

${ }^{3}$ Hind and Randles, Handbook of Photomicrography, p. 238, London, r9r3. 


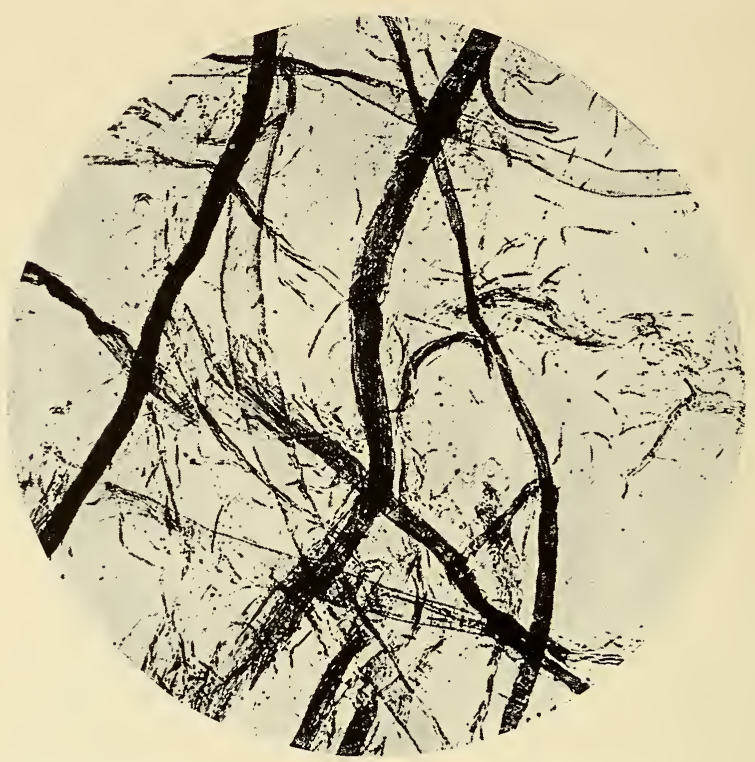

Fig. 27.-Fibers from all rag medium weight bond $\times$ Ioo.

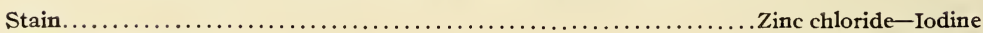

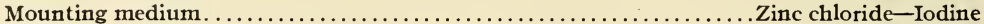

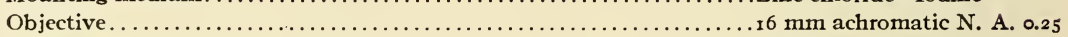

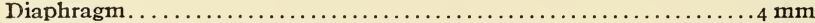

Exposure........................... minutes

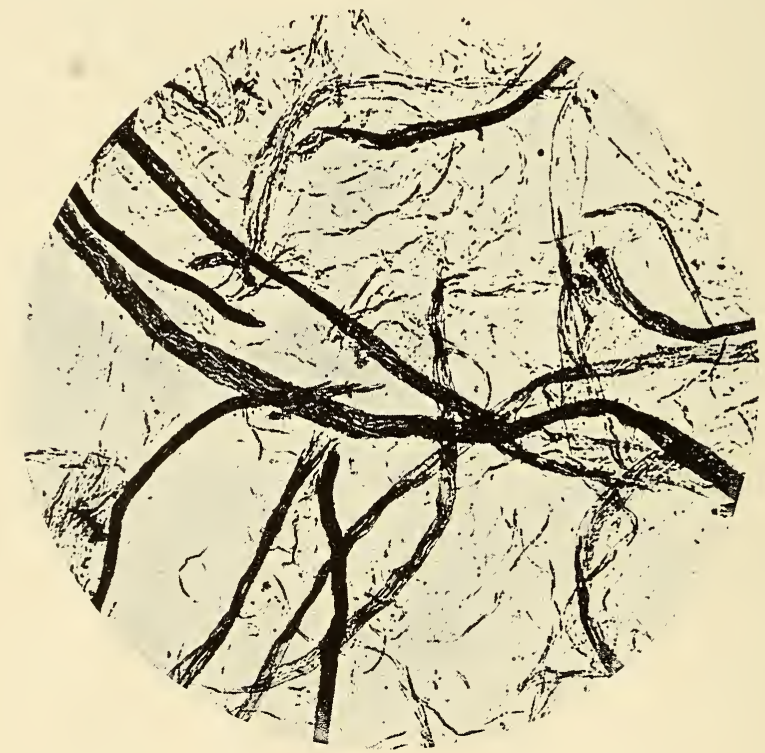

FIG. 28.-Fibers from all rag thin bond $Y_{O O O}$.

Stain.

Mounting medium

Objective

Diaphragm

Exposure.
Zinc chloride-Iodine

Zinc chloride-Iodine

$16 \mathrm{~mm}$ achromatic N. A. 0.25 $4 \mathrm{~mm}$

I $/ 2$ minutes 
paper, and in many other ways. Whatever the eye can see by the aid of the microscope may be recorded photographically if proper methods are used.

Photographs 26,27 , and 28 show the differences in beater treatment for (26) ledger paper, (27) medium-weight bond, and (28) thin bond, and indicate the value of photomicrographs as permanent records.

\section{BIBLIOGRAPHY.}

A short list of books and articles on photomicrography and closely related subjects.

\section{LIGHT AND OPTICS.}

Bausch \& Lomb Optical Co., Lenses, their history, theory, and manufacture; Rochester, N. Y., rgo6.

Beck, Conrad, and Andrews, Herbert, Photographic lenses, 7 th edition; R. \& J. Beck (L,td.), 68 Cornhill, I.ondon.

Daniell, A., A text-book of the principles of physics; Macmillan \& Co., New York and London.

Edser, Edwin, Light for students; Macmillan \& Co., London, 1907. (Elementary, but very complete.)

Lummer, O., and Thompson, Silvanus, Contributions to photographic optics; Macmillan \& Co., New York, I 900.

Watson, William, A text-book of physics; Longmans, Greene \& Co., New York and London.

Microscopy.

Bausch, E., Manipulation of the microscope; Roclester, N. Y., rgo6.

Carpenter-Dallinger, The microscope and its revelations; P. Blakiston's Son \& Co., Philadelphia, I9I3.

Chamot, Emile Monnin, Elementary chemical microscopy; John Wiley \& Sons, New Iork, I920.

Gage, Simon Henry, The microscope, an introduction to microscopic methods and to histology; The Conıstock Publishing Co., Ithaca, N. Y., ro20. (Very good.)

Hanausek, T. F., and Winton, Andrew L., The microscopy of technical products; John Wiley \& Sons, New York, 1907.

Hogg, Jabez, The microscope, its history, construction, and application; George Routledge \& Sons (Ltd.), London, Igr.. (Very complete.)

Lee, A. B., The microscopist's vade-mecum; P. Blakiston's Son \& Co., Philadelphia, I9I3.

Microscopy of pulpwoods, Paper 26, 19; April 21, I920.

Spitta, Edmund, Microscopy, the construction, theory, and use of the microscope; John Murry, London, rgc9.

Stokes, Alfred, Aquatic microscopy for beginners; John Wiley \& Sons, New York, I918.

The microscope, its design, construction, and applications, J. Roy. Microscopical Soc., Part 4; Dec., I920. See copies of above in Fingineer, 129, p. 85-87, Jan. 23, I920, and in Engineering, 109, p. 86-87, and 106/7, Jan. I6 and 2.3, I920. (See current and back numbers of J. Roy. Microscopical Soc., and of Tran. of Am. Microscopical Soc. for articles dealing with all phases of microscopical work.)

Whipple, G. C., The microscopy of drinking water; John Wiley \& Sons, New York, I9I4. 


\section{PHOTOGRAPHY.}

Bayley, R. Child, The complete photographer; McClure, Phillips \& Co., New York, 1907 .

Derr, Louis, Photography for students of physics and chemistry; Macmillan \& Co., New York, I9o6.

Flint, William Ruthven, Chemistry for photographers; American Photographic Publishing Co., Boston, r9r6. (See current and back numbers of the various photographic periodicals, American and British, and especially the British Journal Photographic Almanac, published annually by Henry Greenwood \& Co., 24 Wellington Street, Strand, London.)

Johnson, George L., Photography in colours; E. P. Dutton \& Co., New York, I9r 7 .

Taylor, J. Traill, The optics of photography and photographic lenses; Whittaker \& Co., New York, rgo4.

Tennant, John A., Coloring lantern slides; Tennant \& Ward. New York, I907. (Write the publishers, ro3 Park Avenue, New York, for a list of publications dealing with all phases of photography.)

\section{PHOTOMICROGRAPHY.}

Barnard, I. Edwin, Practical photomicrography; E. Arnold, Iondon, rgr r.

Central scientific company (460 Fast Ohio St., Chicago, I11.), Bulletin $95 \mathrm{~S}$, "gives a complete explanation of the application of color filters to photonicrography.'

Experiments in ray collecting and filtering for microscopists; Sci. Am. Sup. 86, 407; June 29, I9I8.

Gage, S. H. and H. P., Optic projection; Comstock Publishing Co., Ithaca, N. Y., I914. (See especially chapters 9, "The projection microscope," ro, "Drawing and photography with projection apparatus," and $\mathrm{x}$, "'Optics of projection.")

Hind, H. Lloyd, and Randles, W. Brough, Handbook of photomicrography; George Routledge \& Sons (Ltd.), Iondon, I9r3. (One of the very best books in English on this subject.)

Light filters and histological dyes for photomicrographic work; Brit. J. Photography, 56, p. I95.

WASHINGTON, January 31, 1922. 